mitral anulus. It was seen in the parasternal long- and short-axis and apical 4-chamber views (Fig. 1). There was an opening of about $1 \mathrm{~cm}$ in the middle of this structure. At operation a fibromuscular diaphragm was found and resected at the typical location. There was a hole about $1 \mathrm{~cm}$ in diameter in the middle of it.

Case 2: A 38-year-old man presented with severe dyspnea on exertion and at rest and atypical chest pain. The second heart sound was loud, and the patient had been in atrial fibrillation for 6 years. Cardiac catheterization in 1979 disclosed pulmonary pressure of 80/53 $\mathrm{mm} \mathrm{Hg}$. Two-dimensional echo in February 1985 revealed a bright, echo-dense structure in the left atrium at a location similar to that in case 1 . There was $a$ small atrial septal defect just cephalad to the membrane. Contrast echo study indicated only a small negative jet. A large left atrial thrombus almost completely filled the superior left atrial chamber (Fig. 2). At operation, the large thrombus was removed and the left atrial "membrane," which had an opening of about
$1 \mathrm{~cm}$ in diameter, was resected. A small foramen ovale was found just above the membrane. Postoperative recovery was uncomplicated.

The diagnostic accuracy of 2-D echo in cor triatriatum has been questioned. ${ }^{5}$ Two-dimensional echo appeared useful in the diagnosis in our patients, in whom both clinical presentation and cardiac catheterization had led to false diagnosis for 6 to 11 years. Successful surgery was performed on the basis of the 2-D echo diagnosis in both cases.

1. Marin-Garcia J, Tandon R, Lucas RV, Edwards JE. Cor triatriatum: study of 20 cases. Am I Cardiol 1975;35:59-66.

2. Richardson JV, Doty DB, Siewers RD, Zuberbuhler JR. Cor triatriatum (subdivided left atrium). I Thorac Cardiovasc Surg 1981:81:232-238.

3. Arciniegas E, Farooki ZQ, Hakimi M, Perry BL, Green EW. Surgical treatment of cor triatriatum. Ann Thorac Surg 1981;32:571-577.

4. Smith T. Silverman NH. Poldershaw CL, Shinebourne EA. Cor triatriatum sinistrum. Diagnostic features on cross-sectional echocardiograph. Br Heart 1984;51:211-219.

5. Schlüter M, Langenstein BA. Thier W, Schmiegel WH, Krehber HJ, Kalmar P, Hanrath P. Transesophageal two-dimensional echocardiography in the diagnosis for cor traitriatum in the adult. JACC 1983;2:1011-1015.

\section{Congenital Aortic Arch Thrombosis Diagnosed by Echocardiography}

\author{
WILIAM A. SCOTT, MD \\ A. REBECCA SNIDER, MD \\ MACDONALD DICK, II, MD \\ KATHLEEN P. HEIDELBERGER, MD \\ EDWARD L. BOVE, MD \\ ANTONIO W. PESCHIERA, MD
}

A

ortic thrombosis is rare. The thrombus has usually been located in the descending aorta and is associated with sepsis, maternal antithrombin-III deficiency, umbilical artery catheter complications, maternal diabetes or dilated cardiomyopathy. ${ }^{1-3}$ In 2 cases, the thrombus was located in the ascending and transverse aorta and no cause was found.$^{4,5}$ We describe an infant with ascending aorta thrombosis of unknown origin.

A 2.9-kg boy was born at 36 weeks gestation via spontaneous vaginal delivery. The pregnancy was uneventful except for decreased heart rate variability for 6 hours before delivery. Apgar scores were 0 and 1 at 1 and 5 minutes. The infant was resuscitated and transferred to a regional neonatal care facility. Over the next 2 days the infant had respiratory distress, severe hypotension and cerebral edema. Because of poor pulses and an echocardiogram that was interpreted as showing interrupted aortic arch, the infant was transferred to the university hospital for cardiac evaluation. Physical examination showed poor perfusion and

From the Department of Pediatrics C.S. Mott Children's Hospital University of Michigan Medical Center Ann Arbor, Michigan 48109-0204. Manuscript received July 7, 1986; revised manuscript received August 1, 1986, accepted August 4, 1986. absence of pulses in all extremities and both carotid arteries. Electrocardiographic findings were normal. Chest $\mathrm{x}$-ray showed moderate cardiomegaly and normal pulmonary vascular markings. The initial echocardiogram was interpreted as showing aortic arch interruption, patent ductus arteriosus and poor left ventricular function. At catheterization, simultaneous left ventricular and descending aortic pressures were $160 / 25$ and $57 / 43 \mathrm{~mm} \mathrm{Hg}$. An umbilical artery catheter was advanced retrogradely into the left ventricle, but this maneuver was poorly tolerated. On pullback, a $35-\mathrm{mm} \mathrm{Hg}$ gradient was recorded across the aortic

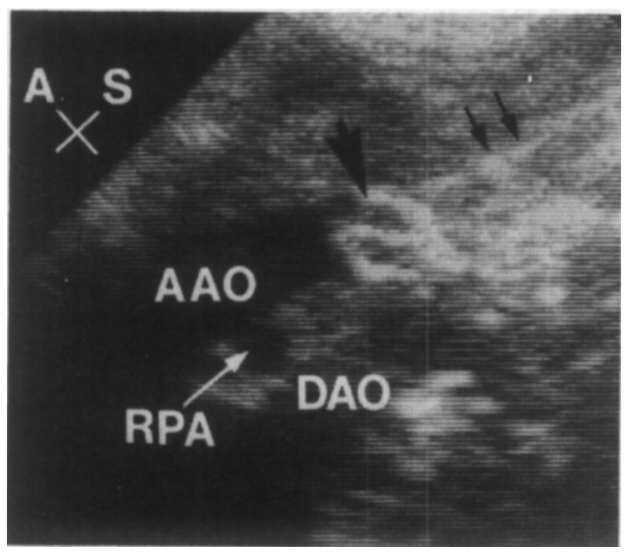

FIGURE 1. Suprasternal long-axls vlew of the aortic arch. Dense echoes (large arrow) are seen filling the ascending aorta (AAO) proximal to the origin of the innominate artery and exiending around the aortic arch. These echoes arise from an organized aortic thrombus. Note the irregular borders of the thrombus and the absence of Imaging of any vessels to the head and neck. Dense echoes (small arrows) are also seen in the reglons usually occupled by the head and neck vessels and probably arise from thrombus extending into these vessels. $A=$ anterlor; DAO = descending aorta; RPA = right pulmonary artery; $S=$ superior. 


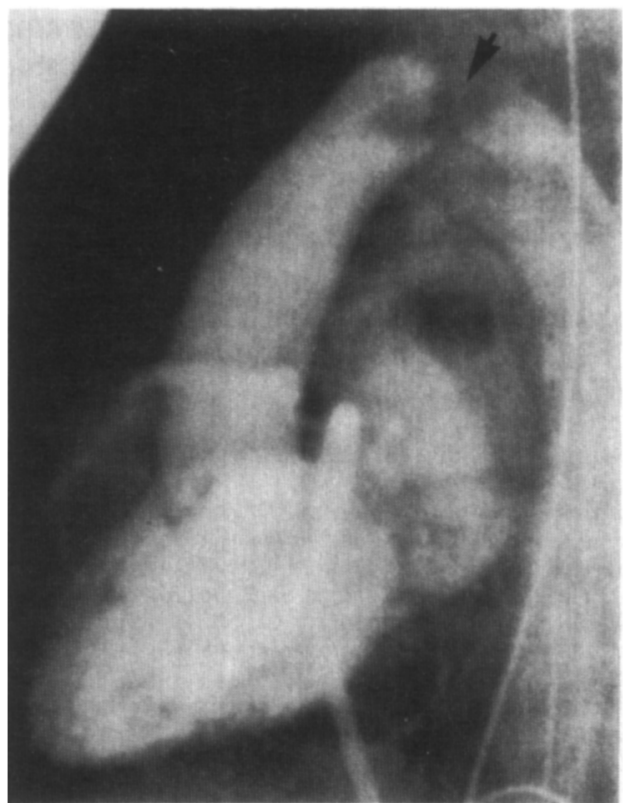

FIGURE 2. Left ventricular cineangiogram in the lateral projection. A large filling defect (arrow) with irregular borders is seen in the transverse aorta. This filling defect represents thrombotic occlusion of the aortic arch. The descending aorta opacifled by way of a patent ductus arteriosus. Note absence of opacification of head and neck vessels.

valve. Catheterization findings were interpreted as showing severe tubular hypoplasia and coarctation of the aortic arch. At surgery, the entire transverse aorta and the head and neck vessels were occluded by thrombus. A large amount of occluding thrombus was removed, a patch was placed on the descending aorta and the patient ductus arteriosus was ligated. Initially, perfusion and blood pressure were good, but 12 hours after operation, the patient suddenly died.

On reexamination of the echocardiogram a day later, an irregular echo-dense mass was seen in the ascending aorta proximal to the origin of the innominate artery, and it extended to the origin of the left subclavian artery (Fig. 1). No aortic lumen was seen. The innominate, left common carotid and left subclavian arteries were occluded by the echo-dense material. The cineangiograms (Fig. 2) were reviewed after the infant's death and, in retrospect, showed an irregular filling defect in the ascending aorta extending around the aortic arch. No head and neck vessels were opacified. At autopsy (Fig. 3), an organized, partiully calcified thrombus was found in the ascending and transverse aorta, obstructing the orifices of the innominate, left common carotid, and left subclavian arteries. The aortic valve was normal and there was no evidence of coarctation of the aorta. Laboratory studies showed no evidence of sepsis, maternal diabetes or maternal antithrombin-III deficiency.

This report describes the third newborn with aortic arch thrombosis. All 3 reported infants with this disorder presented with severe congestive heart failure, left ventricular dysfunction and absent peripheral pulses suggesting aortic coarctation or interruption. ${ }^{4,5}$ In our infant, several echocardiographic findings were pres-

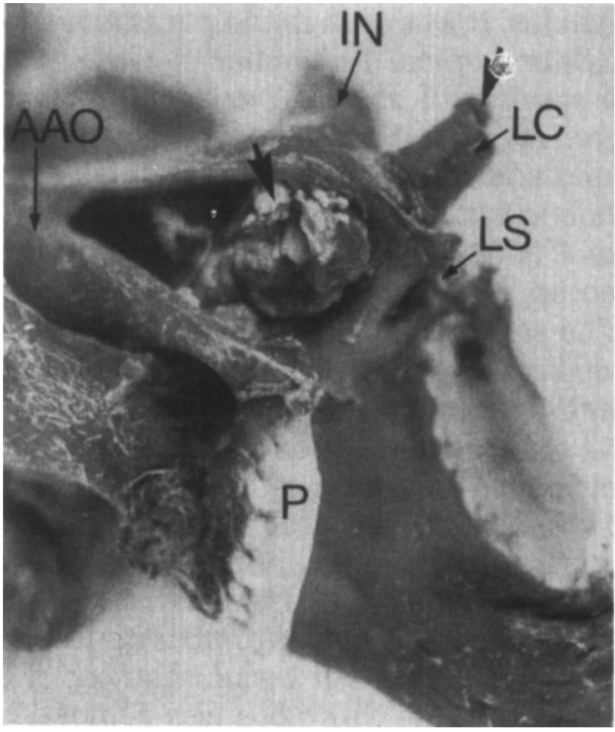

FIGURE 3. The aortic arch opened at the time of autopsy to show thrombus (arrows) in the ascending aorta (AAO) and aortlc arch and protruding from the cut edge of the lett common carotld artery (LC). The surglcal patch (P) is seen on the descending aorta. IN = innominate artery; LS = left subclavlan artery.

ent that allowed us to distinguish this defect from coarctation or interruption of the aortic arch. On the suprasternal notch view (Fig. 1), the distal end of the ascending aorta and the proximal end of the descending aorta had irregular borders and the head and neck vessels were not seen. In interrupted aortic arch, the distal end of the ascending aorta is smooth and rounded and the head and neck vessels are easily imaged. ${ }^{6}$ In type B interrupted aortic arch, the ascending aorta and the 2 carotid arteries form a characteristic "V" pattern. Also, in this infant, the area normally occupied by the aortic arch was filled with a material with an echo density greater than that of the surrounding soft tissues. This finding suggests that an echo-dense mass was occluding the aortic arch rather than that the arch was absent or interrupted in this segment.

No infant with congenital thrombotic occlusion of the aortic arch has survived. In our case, the total occlusion of all vessels supplying the brain probably contributed to the infant's death. Two-dimensional echocardiography provides a safe, noninvansive technique for earlier detection of this disorder.

Acknowledgment: We thank Margaret Young for assistance in the preparation of this manuscript.

1. Bjarke B, Herin P, Blomback M. Neonatal aortic thrombosis: a possible clinical manifestation of congenital antithrombin III deficiency. Acta Pediatr Scand 1974;63:297-301.

2. Marsh JL, King W. Barret C, Foncalsrud EW. Serious complications after umbilical catheterization for neonatal monitoring. Arch Surg 1975;110:12031208.

3. Knnwlson GT, Marsden HR. Anrtin thrombosis in the newhorn period. Arch Dis Child 1978;53:164-166.

4. McFaul RC, Keane JF, Nowicki ER, Castaneda AR. Aortic thrombosis in the neonate. I Thorac Cardiovasc Surg 1981;81:334-337.

5. Trowitzsch E Bernsau U, Luhmer I, Merkle W, Kallfelz HC. Congenita thrombotic occlusion of the ascending aorta and the aortic arch. Pediatr Cardiol 1985;6:165-169.

6. Snider AR, Silverman NH. Suprasternal notch echocardiography: a twodimensional technique for evaluating congenital heart disease. Circulation 1981;63:165-173. 